\title{
Pursuing Change in a Learning University: The Role of the Dean
}

\author{
Marc R. Usunier \\ University of Saskatchewan \\ Vicki Squires \\ University of Saskatchewan
}

The pursuit of change in any formal organization is challenging. Change within a university is further complicated by context. As mid-level leaders within universities, academic deans find themselves at the center of these change initiatives. They experience a variety of difficulties in their role as change-leader. Using Senge's (1990; see also Senge, 2006) learning organization theory, it is possible to better understand how deans navigate university labyrinths in their pursuit of change, how they can foster a culture of learning within their organizations to support future change agendas, and what difficulties they can experience in pursuit of these changes.

\section{INTRODUCTION}

The pursuit of change in any formal organization is challenging. Change within a university is further complicated by context. As mid-level leaders within universities, academic deans find themselves at the center of these change initiatives. They experience a variety of difficulties in their role as change-leader. Inhibited by context, tensions with faculty, governance and structural limitations, and external and internal constituents, deans pursue change agendas in one form or another throughout their tenure (Arntzen, 2016; Bess \& Dee, 2014; Bolman \&Gallos, 2011; Hendrickson et al., 2013; Kezar\& Eckel, 2004; Morris, 1981). The role of the leader is central to the success of any change process. Using Senge's (1990; see also Senge, 2006) learning organization theory, it is possible to better understand how deans navigate university labyrinths in their pursuit of change, how they can foster a culture of learning within their organizations to support future change agendas, and what difficulties they can experience in pursuit of these changes.

\section{CHANGE IN A COMPLEX CONTEXT}

Universities operate in increasingly complex contexts. In addition to fulfilling teaching and learning mandates, universities must engage the community, facilitate research that supports the development of an equitable society, and enhance the regional and national economy through scientific innovation (Rich, 2006). In the recent past, austerity budgets and increasing student demands have further compounded these pressures (Kezar\& Eckel, 2004). Such challenging contexts impact the governance procedures within universities. University administrators are being asked to make decisions on much shorter 
timelines than they are accustomed, and the dividing lines between the responsibilities of various senior administrators blur as universities become flatter in hierarchical structure in an endeavor to keep pace with the rapidly changing world (Boyko \& Jones, 2010). In their role as mid-level leaders, it falls to academic deans to ensure colleges or faculties (depending on the context) remain flexible enough to be responsive to and thrive within these changing contexts, but resilient in maintaining high academic standards, offering engaging programming, and facilitating research that has a social utility.

The complex and shifting contexts in which universities operate has led to a shift in what it means to be successful as a dean within a university (de Boer \&Goedegebuure, 2009). This definitional difficulty is further exacerbated by the declining political priority of higher education, and budgetary concerns brought on by decreased government funding and increased demands to limit tuition fee increases (Rich, 2006). The limitations and high expectations that result from this shift increase the pressure on universities and their leaders to demonstrate their efficiency, productivity, efficacy, and relevance in today's world. It is crucial that deans can effectively play the role of facilitator, negotiator, and alliance builder (Rosser, Johnsrud, \& Heck, 2003) within their college and between various on- and off-campus constituents. Morris (1981) contended that the success of a dean is determined by their ability to stroke, cajole, cultivate relationships with, and keep in line various constituents. To be successful in the contemporary university, deans must support and appease those above them in the vertical power hierarchy (Bess \& Dee, 2008) while attempting to persuade and coax independent, libertarian faculty members within their college (Rich, 2006).

\section{The Relationship Between Faculty and the Dean}

The relationship between a dean and their faculty is central to the context of any academic college. Bess and Dee (2014) contended that animosity between faculty and administration is ubiquitous on most university campuses. They argued that such hostility is especially prevalent in times of disagreement over budgetary cuts and reorganization plans. Not only do deans and senior administrators have to navigate external complexities in their attempts to work within imposed financial constraints, but they also have to mollify internal constituents to secure the license to pursue their change and reorganization initiatives. These internal power dynamics can impact campus morale, often leading to the all-to-familiar us (faculty) versus them (administration) mentality. Morris (1981) based such dichotomies on the misunderstandings and misgivings faculty have of senior administrative roles. Faculty are not necessarily encouraged to be aware of senior administrative processes, and as faculty perceive directives from deans as related to linemanagement leadership rather than to the teaching and researching activities of faculty, decanal directives are regularly ignored. Given this historically troubled relationship, the role of faculty in academic governance can be problematic for a dean (Boyko \& Jones, 2010). Bolman and Gallos (2011) argued that deans can enhance their likelihood of working successfully alongside faculty by understanding the connections between thinking, learning, and taking effective action; the subtleties and challenges of the academy; and developing longer-term strategies for sustaining themselves in their leadership positions.

\section{The Importance of Understanding a University's Governance, Structure, and Culture}

The relationships between faculty members and senior administrators is not the sole influencer on university governance. External influencers and continually changing environments are having more of an impact on what takes place within the university than ever before (Hendrickson et al., 2013). To succeed in this environment deans have to develop a wide-ranging understanding of how both their college and university is structured and identify where institutional decision-making power rests (Hendrickson et al., 2013). They need to familiarize themselves with the culture of the organization and the organization's role within the community to better position themselves to pursue their change initiatives. For the purposes of this paper, organizational culture is defined as the predominant patterns of thoughts, feelings, and actions that are formally or informally encouraged within an organization (Fincher, 1986).

To ensure the viability and relevance of universities, structures and practices within universities must change to meet the ever-shifting public needs (Antony, Cauce, \& Shalala, 2017). Antony, Cauce, and Shalala (2017) postulated that effective administrative leadership is essential to achieving this type of 
change. To develop effective administration, academic leaders must first interpret and understand the specific culture of a given institution. While there are some similarities in how universities as organizations have evolved (sometimes over the course of several hundred years), specific social contexts and geographical locations exert particular influences on how this evolution manifests itself, resulting in universities that have significantly different governance models (Harvey, Shaw, Mcphail, \& Erickson, 2013). In turn, their organizational culture differs, as do the qualities that make a successful academic leader within that organization.

Historical, geographical, social, and cultural influencers all affect the makeup of a university and how successful deans navigate and lead within that specific context. Leading through or during times of organizational, structural, or programmatic change further complicates the leader's role (Taylor \& Machado, 2006). Unlike in private corporations where senior leaders can simply terminate someone who disagrees with their change initiative or tries to obstruct it, working through the collegial process with tenured faculty in the highly unionized environment of a university is more complicated (Bess \& Dee, 2008; see also Hendrickson, Jason, Harris, \& Dorman, 2013). The dean of a college has little disciplinary power over the faculty they lead. This lack of positional authority results in a power dynamic that is entirely unlike anything in the corporate world (Bess \& Dee, 2008) and results in a drastically different organizational culture and organizational learning than in more corporatized organizations. Furthermore, the goals of universities and their values, mission, and history differentiate them from large corporations (Velcoff\& Ferrari, 2006). However, this differentiation does not negate the application of organizational learning theories to understanding universities and how leaders within them pursue change (Argyris \& Schon, 1996; see also Bolman \&Gallos, 2011; Senge, 1990).

\section{UNIVERSITIES AS LEARNING ORGANIZATIONS}

Facilitating a culture of learning is one of the highest goals to which an organization can strive (Čierna et al., 2017). Learning organizations successfully augment their processes to ensure maximized use of employee potential. Senge (1990) defined the learning organization as an "organization where people continually expand their capacity to create the results they truly desire, where new and expansive patterns of thinking are nurtured, where collective aspiration is set free, and where people are continually learning how to learn together" (p.3). Learning organizations continually improve (Čierna et al., 2017) and universities continually evolve (Scott, 1993). Using learning organization theory to understand how mid-level leaders facilitate this evolutionary change within universities can lead to a better understanding of the leadership qualities a dean needs to successfully lead their college through organizational change (Čierna et al., 2017).

Senge (2006) identified five dimensions that must be present within an organization to constitute a learning organization - systems thinking, personal mastery, mental models, building shared vision, and team learning. Systems thinking, also referred to as the "fifth discipline," brings all other dimensions together, and is evidenced by an organization thinking of a problem in its entirety rather than breaking it down into smaller parts. Systems thinking facilitates the identification of patterns and how to efficiently change them. Personal mastery is a level of proficiency. This proficiency involves continual revision, deepening, and expounding of our personal vision(s) and further enhancing our objective abilities. Senge (2006) understood mental models as the deep-seated assumptions and stereotypes that influence how we perceive the world and respond to various stimuli. Building a shared vision increases the likelihood that people will excel and learn within an organization. Shared visions turn the deeply-held views and goals of the few into the mission and mandate of the many. While most organizations lack the mechanisms to translate from the individual to the group, this shared vision for the future is essential to the learning organization. Team learning is the final dimension. Senge (2006) argued that teams or groups of individuals can learn. For him, the process begins with a dialogue that leads to interrupting assumptions and thinking as a group. Team learning is essential to the process of organizational learning as teams, not individuals, are the central learning unit of modern organizations (Senge, 2006). 


\section{Facilitating the Culture of a Learning Organization}

Academic deans foster or hinder the learning mentality within their organization (see Figure 1). While it may be advantageous for a dean to surround themselves with highly-skilled administrative staff who can enhance the work of the dean, fostering an environment conducive to a learning organization demands resources and strategic effort. Arntzen (2016) noted that the role of a dean as a manager of people is to energize and provide opportunity for staff development, and to strengthen organizational culture. Deans are typically busy individuals. They have meetings to attend, donors to engage, a college to run, and depending on the situation a research profile to maintain (Boyko \& Jones, 2010). Given their busy schedules, the feasibility of creating an environment conducive to this type of learning takes a concerted effort. Leading by example can only take an organization so far. Appropriate mechanisms, systems, and priorities that foster institutional learning are necessary to ensure organizational members are able and encouraged to develop their capacities and enhance their skill set.

\section{Deans as Designers, Teachers, and Stewards}

Senge (2006) argued that there are three types of leaders within learning organizations. Leaders who are designers use or create institutional artifacts to facilitate the growth and engagement of their staff. They are the architects of their organizations. Leaders as teachers engage others in the learning process. They both create the space for organizational learning to take place and invite others to join them in it. Finally, leaders as stewards serve those whom they lead in furtherance of a larger goal. Senge's (2006) concept of steward leaders aligns in many ways with Greenleaf's (1996) notion of servant leadership. While no single dean can be a designer, teacher, and steward, the necessity of these specific leadership capacities is directly related to the needs of a given college at a specific point in time.

\section{External Influencers}

Universities are typically motivated to change by external influencers (Kezar\& Eckel, 2004; see also Rich, 2006; Rosser et al., 2003). External influencers can take a variety of forms. In Canada, provincial governments can exert their influence through their control over a university's operating grant (Boyko \& Jones, 2010). The federal government can influence the research agenda of an institution or group of institutions by identifying priority research areas and allocating funding accordingly. The broader public applies their influence through demands for increased accountability, ensuring the university maintains an active presence in the local community, and regular calls for affordable tuition. Global demand for access to higher education also influences actions taken within universities (Rich, 2006). Universities do not exist or operate in a vacuum; the "ivory tower" is very much influenced by the outside world, as are the deans who lead within it.

A dean who can approach an issue or problem with an understanding of the wider context is far more likely to be successful in their role. Senge's (2006) theory of organizational learning defines this process as systems thinking. A systems thinker uses their knowledge of the relationships between a university and government to inform their change or decision-making process. Not only does this occur at the macro institution to institution level, but at the individual level as well. That the percentage of time a dean spends working with external stakeholders continues to increase is demonstrative of the increased realization amongst deans of the importance of being aware of and proactively engaging with the wider environment (Engwall, 2014; see also Rich, 2006).

Senge (1990) understood systems thinking as a conceptual framework that helps individuals make theoretical differentiations and organize ideas. A dean or perhaps a dean and his leadership team collects and organizes information regarding external constituencies and the roles (levels of power) they play within the wider community to inform their future decision-making processes. Specifically, when decisions to change major aspects of a college are under discussion, the perceived opinion of that change by relevant government ministries and the broader public is considered. If such considerations were not the impetus for the change initiative, they would certainly inform them. Provincial governments in Canada and Canadian universities are all-to-often positioned at opposite ends of the ideological spectrum on a variety of issues (Usher, 2017). The astute dean will therefore always be aware of how proposed 
changes fit into this meta narrative. Their political astuteness and ability to observe, think, and interpret from a systems level will inform their ultimate decision.

External influences also impact a leader's vision. Leaders instinctively work towards a goal that is both good for the organization and themselves. For this to be true, these goals and vision need to align, at least in part, with those of the wider community. The wise dean continually reevaluates their plans in light of government priorities and shifts in the wider public opinion. Senge (2006) described this ability as personal mastery, or a level of proficiency that enables a leader to know both themselves and their context(s) well enough to be able to continually reevaluate their personal visions and reality, and focus their efforts based on these inputs. Although few institutions encourage and facilitate this aspect of organizational learning, it is essential in the development of informed leaders.

Understanding the mental models an academic dean develops through their experiences with external stakeholders also furthers the understanding of external influences on academic colleges and the wider universities of which they are a part. Senge (2006) used mental models to signify the deeply held assumptions, generalizations and stereotypes that are held by individuals. These models shape an individual's perception of the world around them and their responses to stimuli in their environments. The image of a dean as a coordinator and coalition builder that Arntzen (2016) referred to is a result of the common mental model that has largely been adopted by academic deans. Out of necessity, they develop a generalization of what stakeholders are looking for in an academic dean. They try as best as they can to fit into these expectations and adjust their mental model accordingly. However, when the expectations are unclear or shift this becomes problematic. Lack of clarity around role can lead to the failure of a dean and a dean's change initiatives simply because there is no clear definition of success (Harvey et al., 2013).

\section{Internal Influencers}

Internal constituents can also influence university change initiatives. Academic deans need to be able to navigate the labyrinth of both the internal governance structures and political influencers they encounter in their roles to further their change agendas. Rosser, Johnsrud, and Heck (2003) identified deans as slaves to two masters. Within the university system, deans are expected to be generative, interpretive, and inspirational leaders (Bolman \&Gallos, 2011), and must also work to support the activities of their faculty while promoting the agenda of central administration (Antony et al., 2017). Understanding how deans can navigate and be successful within such a demanding environment is possible through the lens of organizational learning theory. Deans must be systems thinkers. Not only must they employ a strong understanding of the external environment, but they must also develop a keen awareness of both the formal governance procedures and informal power structures that operate within their specific university.

Governance within universities is in many ways at a crossroads. Kezar and Eckel (2004) noted that faculty involvement in academic governance continues to decline, all while campus senates and governing bodies are being asked to make more decisions in much shorter timeframes than before. Not only are governing bodies being asked to make decisions quicker than ever before, but they are also carrying out this hurried work with a less robust complement of participating faculty than in the past. With universities employing fewer full-time faculty, an increased focus on what is good for the department rather than what is good for the college or wider institution, and no reward for participating, other demands on faculty members' limited time take precedence over governance-related activities (DePaola\&Kezar, 2018; see also Kezar\& Eckel, 2004). The continued lack of participation of this group in the governance process of universities is problematic for academic deans (Bess \& Dee, 2014; see also Carlisle \& Miller, 1998; Kezar\& Eckel, 2004).

To navigate these internal complexities deans rely on their ability to think systematically, to continually enhance their personal mastery (their personal goals and vision in their work), and repeatedly update their mental models based on new information. However, a dean cannot fulfill their mandate or vision on their own. They must also facilitate the growth of their staff in these areas. Senge (2006) postulated that executive leaders are responsible for constructing the overall environment that allows those who work within the organization to pursue change initiatives. This construction includes bringing 
together ideas for improvement, removing or navigating around any structural impediments that prevent change from being possible, and most importantly acting as a role model for the entire organization. For a dean to truly facilitate the establishment and continuation of a learning organization within their academic college, they must be able to both "talk the talk" and "walk the walk."

\section{FIGURE 1 \\ INFLUENCERS ON THE DEAN IN THE DEVELOPMENT OF A LEARNING ORGANIZATION}

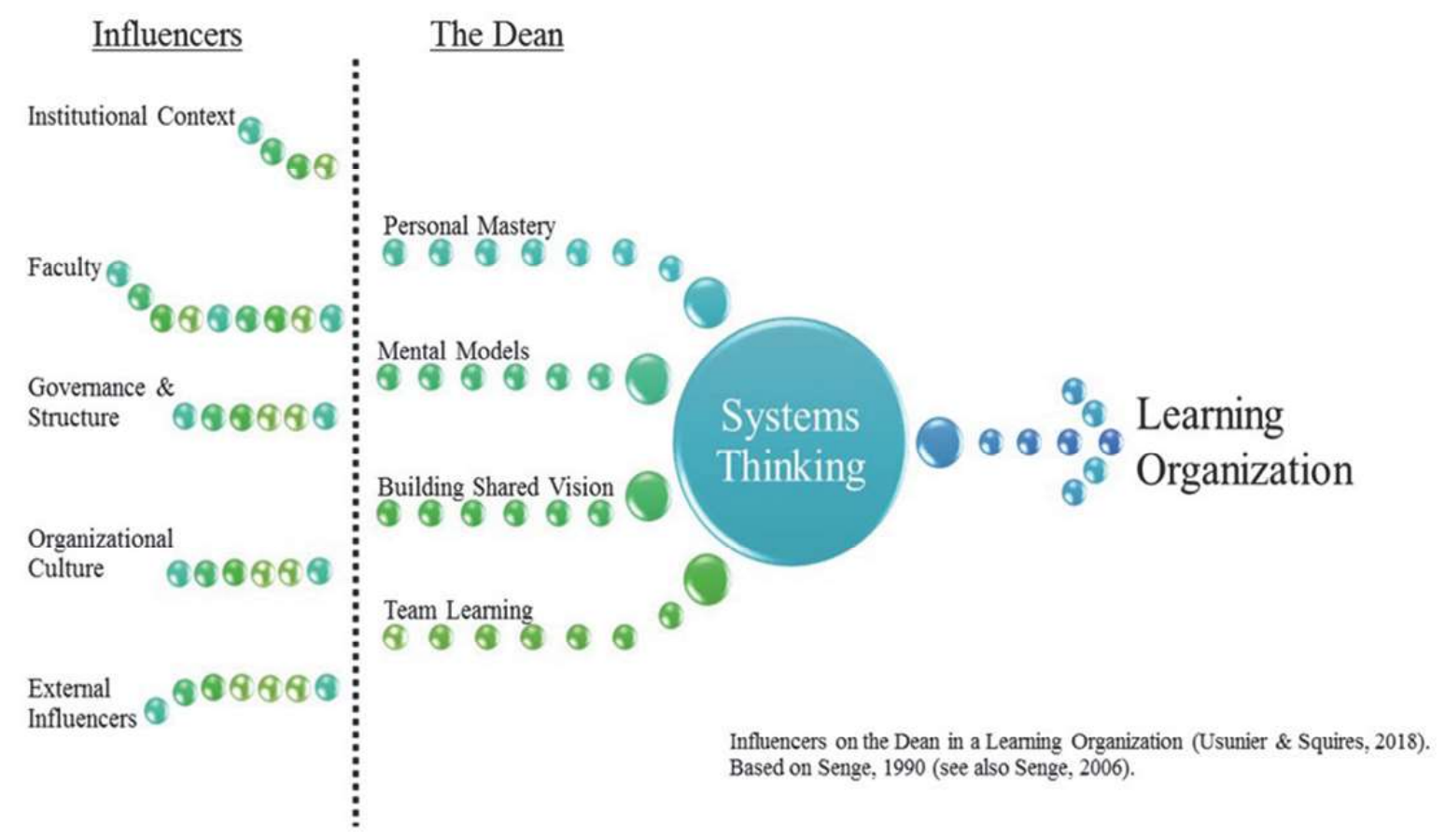

\section{Warrants for Change}

To facilitate or pursue a change agenda within their institution, a dean must first establish a need for that change and receive consent from the wider community to go forward. Antony, Cauce, and Shalala (2017) reasoned that successful redesign initiatives within a university are most likely to succeed if a leader first makes a successful case for the proposed change. This argument should reference at least one of the following general outcomes: increased impact on the wider environment, improving student success and outcomes, or institutional growth (Antony et al., 2017). A charismatic leader who articulates their change agenda in these terms will receive the requisite support of faculty and administration to proceed. The process that Antony, Cauce, and Shalala (2017) articulated specifies the importance of building a shared vision within an organization during times of change. A Dean needs to leverage their skills and charisma as a leader to ensure their personal vision of change becomes the goal of the wider faculty complement. Working through the collegial process with tenured faculty in the highly unionized environment of a university is complicated. The lack of vertical power a dean has in relation to their faculty emphasizes the importance of a dean embracing the role of steward (Bess \& Dee, 2008). Stewards have an underlying belief that motivates their leadership. They do not pursue power for the sake of power, but to achieve an end. Stewards facilitate the initiatives of a group and are strong coalition builders. Leadership is entirely about change (Senge, 2006). Leaders always have new ideas and propose different ways of doing things. However, in academia, the implementation of proposed changes is often secondary to the approach deans employ in instituting these changes (Taylor \& Machado, 2006). A dean must work within both the spirit of collegiality and follow the prescribed process. By building a shared vision 
amongst their faculty and facilitating the collective learning of their college constituents, deans can achieve their goals without upsetting the delicate relational balance between administration and faculty.

\section{Structural Change}

One notable change initiative that deans often pursue is change to the very foundation of organizations - their structures. Before a dean can seek structural change within an organization, they must first understand the intricacies of the organizational structure they have inherited. They need to understand how individuals interact and work within that structure, and identify where decision-making powers are held (Hendrickson et al., 2013). Hendrickson, Jason, Harris, and Dorman (2013) contended that universities are amongst the oldest organizational structures in the world. However, the relative success of these age-old institutions is largely a result of the non-limiting nature of the university as an idea (Scott, 1993). This flexibility in the conception of the university has allowed individual universities and the colleges that constitute them to shift structurally to adapt to the prevailing social, economic, or intellectual trends of any given age.

Structure identifies the deep-seated causes of behaviour within an organization (Senge, 2006). Therefore, the structure of an academic college is important to the success or evolution of that college. Changing the basic structure of an organization changes the behavioural patterns of those within it, which can help to support the attainment of new organizational goals. Designer leaders are typically the most successful in the pursuit of structural change (Senge, 2006). Designer deans recognize that they are a part of their organization and approach it as a living system. These leaders see structural change initiatives as a means of changing how individuals within the system function. For them, altering the structure of an organization is the most efficient and effective means by which they can modify the outcomes of a college to better align with strategic goals and institutional vision.

\section{Goćkowski's Approach}

Goćkowski (2001) contended that in order for structural changes to be truly effective in reaching the ultimate goals of universities and society, they must be a radical and complete shift away from the current system. Traditional departmental structures are the most prevalent model of university organization. Goćkowski (2001) argued that by deviating from this standard organizational structure, institutions can organize faculty around particular research questions and problems. Avoiding the limiting nature of departmental organization in favour of a more fluid, problem-based system would lead to an increased research productivity and focus on research questions relevant to societal needs.

The intent of Goćkowski's (2001) proposed university restructuring in favour of a problem-based system is to alter the structure of academic departments and colleges to enable faculty researchers to think in different ways. Redesigning the often artificial divisions between various academic disciplines will release faculty from thinking solely within departmental borders and foster engagement with extradepartmental colleagues in the pursuit of interdisciplinary research questions (Goćkowski, 2001). The role of the leader in pursuing such radical organizational shifts is particularly important to consider. Establishing a complete structural reorganization as a viable way forward in a collegial environment requires an incredibly convincing argument. A dean needs to have a clear understanding of why this reorganization is necessary, be able to articulate the value of their proposal clearly, outline how they will get there, and be open to continually re-evaluating their approach in light of feedback from faculty (Bolman \&Gallos, 2011).

\section{Challenges in the Pursuit of Change}

Academic deans can face challenges when pursuing change initiatives, and the more substantive or radical the change, the more significant those challenges become. A certain degree of apprehension always accompanies change - it is human nature to be distrustful of change and the unknown that comes with it (Miller \& Monge, 1985). This apprehension is evident in universities as well. To make changes more palatable the change agent (the dean) needs to both be known to the organization and know the organization. Particularly as external candidates are increasingly seen as more suitably prepared to 
assume significant leadership roles (Engwall, 2014), this initial period of getting to know one another takes on an increased importance. Only after a new leader knows the specifics of an organizational context can they begin to identify the structural changes that are needed, the desired cultural changes that such structural changes will elicit (Senge, 2006), and develop a plan to articulate the need for these changes in furtherance of an over-arching goal.

Change initiatives are context-specific (Senge, 2006). Within universities and the academic colleges that comprise these universities faculty are at the center of this context. Although the ever-present conflict between faculty and a dean can often have positive outcomes, destabilizing events such as the introduction of a new dean or the introduction of a change agenda by a current dean can increase the intensity of conflict to unproductive and destructive levels (Bess and Dee, 2014). To avoid such conflict it is important for a dean to know, understand, and respect both the history and the context of the organization they lead (Strom, 2014). This organizational knowledge helps a dean develop a deeper appreciation of the particular talents and aspirations of individual organization members and the organization as a whole (Senge, 2006). These are valuable tools to help a dean to determine how to articulate the worth of proposed changes and to leverage the individual strengths of those within the organization in pursuit of that proposed change or redesign.

The faculty complement of a college is one important contextual consideration. Bess and Dee (2014) contended that the adversarial relationship that develops between faculty and senior administrators is often the result of differing paradigms. For example, a functionalist dean believes that an accurate interpretation of a problem is possible. They also think that they can convince the faculty of the supremacy of their solution to a given problem by providing more information as to why change is necessary. However, a college faculty who is predominantly interpretivist in their outlook sees issues as highly contextualized and would argue that multiple structural or organizational changes can solve any given issue, dependant on one's perspective and role within that organization. Such divergent interpretations of a given situation inhibit the ability of a leader to create a shared vision within their organization. This lack of a shared vision hinders the ability of a dean to articulate both what is not working in the current system, and how that system can be modified to improve outcomes (Senge, 2006). Bridging the gulf between faculty and administrators is particularly important when a dean is trying to establish an urgency to pursue their agenda.

\section{CONCLUSIONS}

The role of the leader is paramount in facilitating an environment conducive to a learning organization. Fostering such an environment often requires a significant alteration of the structures and behaviours encouraged within an organization. A learning organization requires systems thinking where both leaders and their followers can see issues and problems as part of a whole, rather than in isolation. Such an organization encourages decision making based on patterns of change, rather than single instances of an occurrence. Feedback loops are created and continually updated in light of newly received information that encourages continual review of practices and procedures (Senge, 2006). Not only should the dean of a learning organization embody these attitudes and perspectives, but they should also create and encourage a system, structure, and culture that enables those within the organization the time and ability to engage in this type of thoughtful, reflective practice.

Learning organizations are increasingly needed to navigate the complexities of the modern world (Senge, 2006). As universities continue occupy positions of importance in western societies (Scott, 1993), it is particularly important that they are able to function effectively within such complexity. New social pressures and expectations require university colleges and departments to have leaders who are willing and able to modify structures and develop new programming to meet societal needs and expectations. If those who lead in universities want universities to maintain their prominent place in society, they must be

able to facilitate the necessary reorganization and redesign to meet the changing needs and demands brought about by economic, political, and technological influences (Havlicek \& Pelikan, 2013). As midlevel leaders, deans are at the center of this continual push for change. Their leadership in pursuit of 
change is the foundation of a successful university. While academic deans certainly do not pursue such transformation on their own, they do play a central role in creating the environment in which this transformation take place.

Academic deans can face many challenges in their roles, particularly as they pursue changes within the organizations they lead. Employing Senge's (1990; see also Senge, 2006) theory of organizational learning in the analysis of the role of a dean in leading such change initiatives enables a clearer understanding of the means by which deans pursue change and the pitfalls they can encounter. Through an exploration of institutional context, the relationship between faculty and senior administrators, university governance and structural limitations, and external and internal constituents, a more precise picture of the role of an academic dean is possible. As leader of a college, establishing and enhancing an organizational culture that fosters the development of a learning organization is of the utmost importance. However, to pursue the aggressive change-mandates academic deans receive, they must first create an environment in which pursuit of such change is possible.

\section{REFERENCES}

Antony, J. S., Cauce, A. M., \& Shalala, D. E. (Eds.). (2017). Challenges in higher education leadership: Practical and scholarly solutions. New York, NY: Routledge.

Argyris, C., \& Schon, D. A. (1996). Organizational learning II: Theory, method and practice. Reading, MA: Addison-Wesley.

Arntzen, E. (2016). The changing role of deans in higher education: From leader to manager. Universal Journal of Educational Research, 4(9), 2068-2075. doi: 10.13189/ujer.2016.040918

Bess, J. L., \& Dee, J. R. (2008). Understanding college and university organization: The state of the system. Sterling, VA: Stylus Publishing.

Bess, J. L., \& Dee, J. R. (2014). Bridging the divide between faculty and administration: A guide to understanding conflict in the academy. New York, NY: Routledge.

Bolman, L. G., \& Gallos, J. V. (2011). Reframing academic leadership. San Francisco, CA: Jossey-Bass.

Boyko, L., \& Jones, G. (2010). The roles and responsibilities of middle management (chairs and deans) in Canadian universities. In V. Meek, L. Goedegebuure, R. Santiago, \& T. Carvalho (Eds.), The changing dynamics of higher education middle management. London: Springer.

Carlisle, B., \& Miller, M. (1998). Current trends and issues in the practice of faculty participation in academic governance. Retrieved from http://www.ulm.edu/sharedgovernance/documents/carlise.pdf

Čierna, H., Erika Sujová, B., Patrycja H., B., Elena Horská, B., Zuzana Kapsdorferová, B., \& Sujová erikasujova, E. (2017). Learning organization at higher education institutions in the EU: Proposal for implementing philosophy of learning organization-results from research. Qual Quant, 51, 1305-1320. doi: 10.1007/s11135-016-0332-3

de Boer, H., \& Goedegebuure, L. (2009). The Changing nature of the academic deanship. Leadership, 5(3), 347-364. doi: 10.1177/1742715009337765

DePaola, T., \& Kezar, A. (2018). The changing face of employment at research universities. New Directions for Institutional Research, 2017(176), 83-96. doi: 10.1002/ir.20246

Engwall, L. (2014). The recruitment of university top leaders: Politics, communities and markets in interaction. Scandinavian Journal of Management, 30(3), 332-343. doi: 10.1016/j.scaman.2013.12.005

Fincher, C. (1986). What is organizational culture? Research in Higher Education, 23(3), 325-328.

Retrieved from https://link.springer.com/journal/11162

Goćkowski, J. G. (2001). A University model for multiple problem areas. Higher Education in Europe, XXVI(3), 447-455. doi: 10.1080/0379772012011602

Greenleaf, R. K. (1996). On becoming a servant-leader. San Francisco, CA: Jossey-Bass. 
Harvey, M., Shaw, J. B., McPhail, R., \& Erickson, A. (2013). The selection of a dean in an academic environment: Are we getting what we deserve? International Journal of Educational Management, 27(1), 19-37. doi: 10.1108/09513541311289800

Havlicek, J., \& Pelikan, M. (2013). The globalization of higher education - Be responsible and survive the changes. International Education Studies, 6(4), 217-224. doi: 10.5539/ies.v6n4p217

Hendrickson, R. M., Jason, E. L., Harris, J. T., \& Dorman, R. H. (2013). Academic leadership and governance of higher education: A guide for trustees, leaders, and aspiring leaders of two- and four-year institutions. Sterling, VA: Stylus Publishing.

Kezar, A., \& Eckel, P. D. (2004). Meeting today's governance challenges: A synthesis of the literature and examination of a future agenda for scholarship. The Journal of Higher Education, 75(4), 371-399. Retrieved from http://www.jstor.org/stable/3838739

Miller, K. I., \& Monge, P. R. (1985). Social information and employee anxiety about organizational change. Human Communication Research, 11(3), 365-386. doi: 10.1111/j.14682958.1985.tb00052.x

Morris, V. C. (1981). Deaning: Middle management in the academe. Chicaco, IL: University of Illinois Press.

Rich, D. (2006). Academic leadership and the restructuring of higher education. New Directions for Higher Education, 134, 37-48. doi: 10.1002/he.215

Rosser, V. J., Johnsrud, L. K., \& Heck, R. H. (2003). Academic deans and directors: Assessing their effectiveness from individual and institutional perspectives. The Journal of Higher Education, 74(1), 1-25. doi: 10.1080/00221546.2003.11777185

Scott, P. (1993). The idea of the university in the 21st century: A British perspective. British Journal of Educational Studies, 41(1), 4-25. Retrieved from http://www.jstor.org/stable/3122430

Senge, P. M. (1990). The fifth discipline: The art and practice of the learning organization. New York, NY: Doubleday.

Senge, P. M. (2006). The fifth discipline: The art and practice of the learning organization. New York, NY: Doubleday.

Strom, M. (2014). Leading with wisdom: How wisdom transforms good leaders into great leaders. Milton, Australia: John Wiley \& Sons Australia.

Taylor, J., \& Machado, M. D. L. (2006). Higher education leadership and management: From conflict to interdependence through strategic planning. Tertiary Education and Management, 12(1), 137160. doi: $10.1007 / \mathrm{s} 11233-006-0003-3$

Usher, A. (2017, November 24). Re: Last Orders on Neoliberalism (Neoliberalism Part 5) [Electronic mailing list message]. Retrieved from http://higheredstrategy.com/blog/

Velcoff, J., \& Ferrari, J. (2006). Perceptions of university mission statement by senior administrators: Relating to faculty engagement. Christian Higher Education, 5(4), 329-339. doi:

$10.1080 / 15363750500408090$ 